\title{
"The shape of things to come ...."
}

California is large and varied. Within its borders are the highest peak and the lowest spot, the driest desert and the wettest mountain in the conterminous 48 states. Its long coastline has rugged cliffs and picturesque rocks, dangerous shoals and smooth, sandy beaches.

Volcanoes and Earth forces-including earthquakeshave built California's mountains. Volcanoes have added hot, molten rock from the Earth's interior, making high places where none were before. The Earth forces that produce earthquakes have lifted mountains, using the rocky material of which the land was made. Rocks that may have been formed in the deep sea are, through the movement of Earth, now risen to the heights. Even now, the mountains are growing by earthquake and volcano.

Other forces are changing the landscape, carving it into the spectacular shapes we cherish as the glorious scenery of California. Chief among these is water, in myriad forms. Rushing stream and plunging fall; roaring river and quiet slough; silent lake and pounding surf-all these as well as the raindrops themselves have sculpted California's land. Most striking artist of all was water working as great ice tongues that covered the mountains a few thousand years ago.

The chapters in this book are arranged so as to emphasize these processes of building and changing. The processes have acted through thousands and millions of years to create California as we know it, and are still changing it, even as we watch. 